Images in...

\title{
New onset dyspnoea at 82 years
}

\author{
Arunkumar Panneerselvam, ${ }^{1,2}$ Preetha T T S, ${ }^{3}$ Panneerselvam Subbiahnadar ${ }^{4}$ \\ ${ }^{1}$ Cardiology Department, Eugene Clinic, S K Selvam Hospital, Mettupalayam, India; \\ ${ }^{2}$ Cardiology Department, PSG Institute of Medical Sciences \& Research, Coimbatore, Tamil Nadu, India; \\ ${ }^{3}$ Obstetrics \& Gynaecology Department, S K Selvam Hospital, Mettupalayam, India; \\ ${ }^{4}$ Family medicine Department, S K Selvam Hospital, Mettupalayam, Tamil Nadu, India
}

Correspondence to Dr Arunkumar Panneerselvam, drparun1976@gmail.com

\section{DESCRIPTION}

A 82-year-old woman with sedentary lifestyle presented with New York Heart Association Class IV dyspnoea and orthopnoea of 1 day duration. Clinical examination was unremarkable except for bilateral basal crepitations. There was no murmur on auscultation. Her baseline investigations including blood sugar, urea, creatinine and calcium were normal. Chest x-ray showed pulmonary venous hypertension. Echocardiogram revealed extensive calcification of mitral annulus which caused severe left ventricular (LV) inflow obstruction with gradient of $37 / 17 \mathrm{~mm} \mathrm{Hg}$ (figure 1A,B; video 1). In contrast to rheumatic mitral stenosis, the valve leaflets were of normal thickness and had normal mobility. Degenerative mitral annular calcification is not an uncommon finding in older patients. Rarely, it may lead to significant LV inflow obstruction with pulmonary oedema. ${ }^{1}$ Mitral annular calcification should be included in the differential diagnosis of pulmonary oedema in geriatric patients. She was treated with diuretics and $\beta$ blockers which provided good relief. Patient's symptomatic class will be reassessed on optimal medical therapy and will be considered for cardiac catheterisation followed by mitral valve replacement, if symptoms do not improve with medical therapy. Mitral annular calcification results from a degenerative process in the fibrous skeleton which is probably accelerated by advanced age, hypertension, hypercholesterolaemia, diabetes mellitus and chronic renal failure. Fibrillar alteration of the collagen ultrastructure acts as a nidus for lipid deposition and the subsequent development of small foci of calcification within annulus and at points of interdigitation with ventricular muscle fibres. ${ }^{2}$ The treatment of choice is surgical excision of calcification with valve replacement or repair, if possible. The calcium bar is removed by sharp en bloc dissection followed by annular reconstruction with a strip of untreated autologous or glutaraldehyde-preserved bovine pericardium. Technically both these steps are demanding and lead to significant morbidity and mortality. In the largest published surgical series for mitral annular calcification the operative mortality was $9.3 \%$ compared with $1.5 \%$ in those without calcification. ${ }^{3}$ Nevertheless, operated patients have better quality of life with better survival rates.

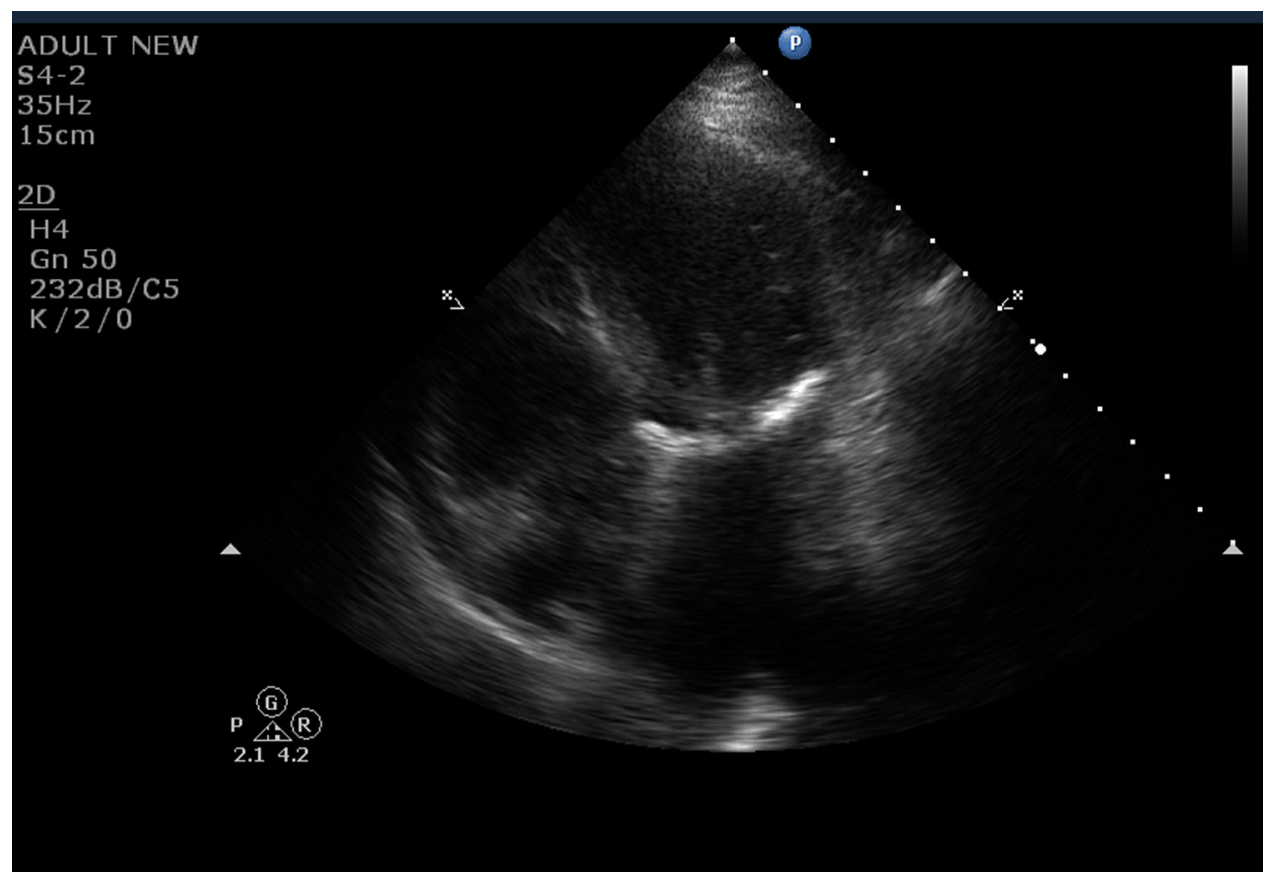

Figure 1 Apical 4-chamber view showing dense calcification of the mitral annulus. Note the thin freely mobile valve leaflets. 


\section{BMJ Case Reports}

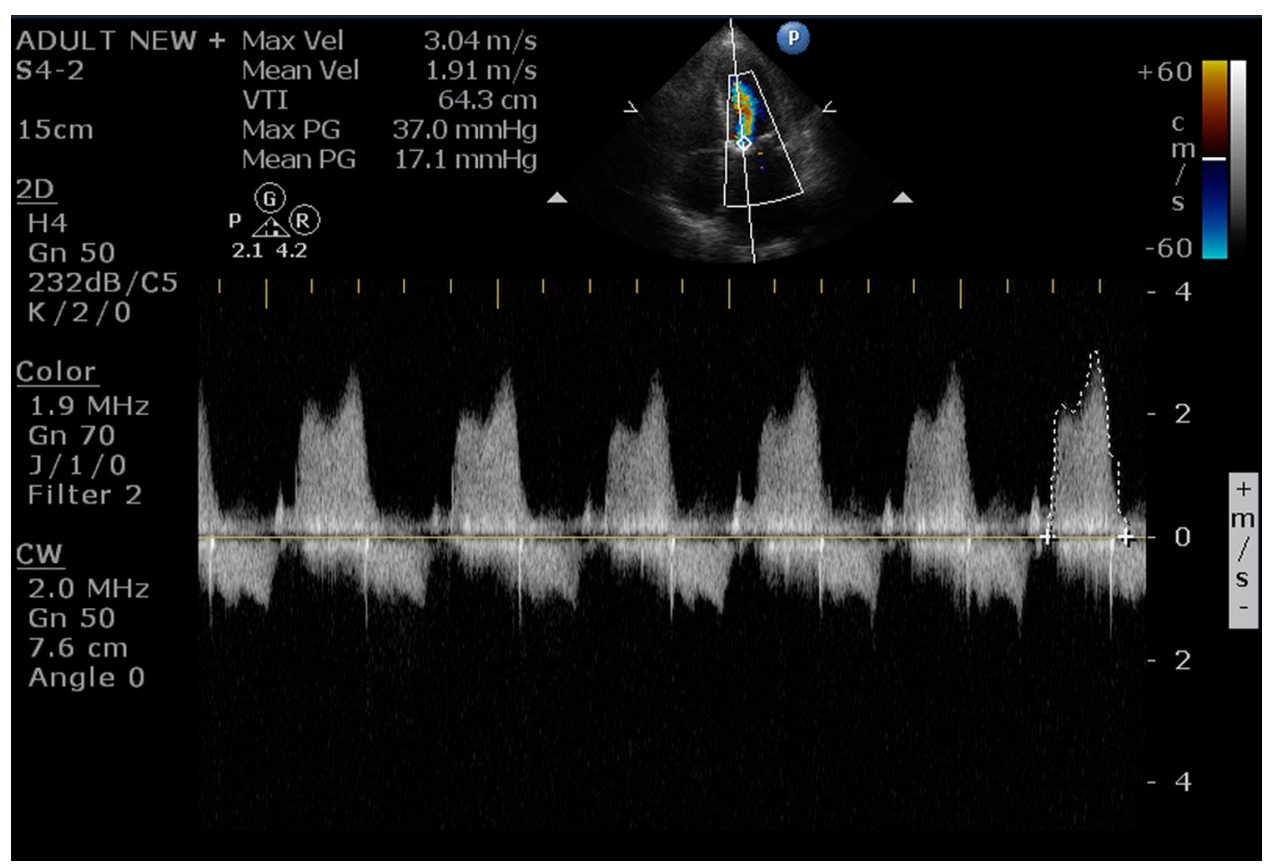

Figure 2 Continuous Doppler across mitral valve demonstrating significant left ventricular inflow obstruction.

Video 1 Apical 4-chamber view showing dense calcification of the mitral annulus. Note the thin freely mobile valve leaflets.10.1136/bcr.03.2012.5978v1

\section{Learning points}

- Mitral annular calcification is not an uncommon cause of $L V$ inflow obstruction.

- Acute pulmonary oedema may be the first and only manifestation.

- Echocardiogram is confirmatory.
Competing interests None.

Patient consent Obtained.

\section{REFERENCES}

1. Pressman GS, Agarwal A, Braitman LE, et al. Mitral annular calcium causing mitral stenosis. Am J Cardiol 2010;105:389-91.

2. Fulkerson PK, Beaver BM, Auseon JC, et al. Calcification of the mitral annulus: etiology, clinical associations, complications and therapy. Am J Med 1979;66:967-77.

3. Feindel CM, Tufail Z, David TE, et al. Mitral valve surgery in patients with extensive calcification of the mitral annulus. J Thorac Cardiovasc Surg 2003;126:777-82.

This pdf has been created automatically from the final edited text and images.

Copyright 2012 BMJ Publishing Group. All rights reserved. For permission to reuse any of this content visit http://group.bmj.com/group/rights-licensing/permissions.

BMJ Case Report Fellows may re-use this article for personal use and teaching without any further permission.

Please cite this article as follows (you will need to access the article online to obtain the date of publication).

Panneerselvam A, Preetha TTS, Subbiahnadar P. New onset dyspnoea at 82 years. BMJ Case Reports 2012;10.1136/bcr.03.2012.5978, Published XXX

Become a Fellow of BMJ Case Reports today and you can:

- Submit as many cases as you like

- Enjoy fast sympathetic peer review and rapid publication of accepted articles

- Access all the published articles

Re-use any of the published material for personal use and teaching without further permission

For information on Institutional Fellowships contact consortiasales@bmjgroup.com

Visit casereports.bmj.com for more articles like this and to become a Fellow

Keep up to date with all published cases by signing up for an alert (all we need is your email address) http://casereports.bmj.com/cgi/alerts/etoc 